\title{
ANALISIS FAKTOR-FAKTOR YANG MEMPENGARUHI PEMBERIAN ASI EKSLUSIF PADA BAYI DI PUSKESMAS TALAGA JAYA
}

\author{
${ }^{1}$ Amanda Adityaningrum, ${ }^{2}$ Herlina Jusuf, ${ }^{3}$ Pradita Pristi Nusi \\ ${ }^{1}$ Fakultas Matematika dan IPA, Universitas Negeri Gorontalo \\ ${ }^{2,3}$ Fakultas Olahraga dan Kesehatan, Universitas Negeri Gorontalo \\ E-mail: amanda@ung.ac.id
}

\begin{abstract}
Exclusive breastfeeding is breastfeeding for 6 months without providing complementary foods or drinks. The health center with the lowest achievement of exclusive breastfeeding, based on data from the Gorontalo Provincial Health Office, is the Talaga Jaya Health Center. The purpose of this study was to determine the factors that influence exclusive breastfeeding for infants at the Talaga Jaya Health Center. This research is a quantitative research. The population is all infants aged 7-11 months totaling 290 people and the sample amounting to 168 people. The sampling technique used is Accidental Sampling and the data analysis used is Logistic Regression. Mother's education, mother's occupation, implementation early initiation of breastfeeding and family support obtained a p-value (0.000) less than (0.05), while the support of health workers had a pvalue (0.998) more than (0.05). The factors that influence exclusive breastfeeding for infants at the Talaga Jaya Health Center are mother's education, mother's occupation, implementation of early initiation of breastfeeding, and family support. It is recommended for family members to be able to participate in exclusive breastfeeding by providing support for mothers breastfeeding up to 6 months..
\end{abstract}

Keywords: Exclusive breastfeeding, IMD, logistic regression.

\begin{abstract}
ABSTRAK
ASI Ekslusif adalah pemberian ASI selama 6 bulan tanpa memberikan makanan atau minuman pendamping. Puskesmas dengan capaian ASI Ekslusif terendah, berdasarkan data dari Dinas Kesehatan Provinsi Gorontalo adalah Puskesmas Talaga Jaya. Tujuan penelitian ini adalah untuk mengetahui faktor-faktor yang mempengaruhi pemberian ASI Eksklusif pada bayi di Puskesmas Talaga Jaya. Penelitian ini merupakan penelitian Kuantitatif. Populasinya adalah seluruh bayi yang berumur 7-11 bulan berjumlah 290 orang dan sampel berjumlah 168 orang. Teknik sampling yang digunakan adalah Accindental Sampling dan analisis data yang digunakan adalah Regresi Logistik. Pendidikan ibu, pekerjaan ibu, pelaksanaan IMD dan dukungan keluarga memperoleh nilai p-value $(0,000)$ kurang dari $\alpha(0,05)$, sedangkan dukungan petugas kesehatan memiliki nilai p-value $(0,998)$ lebih dari $\alpha(0,05)$. Faktor-faktor yang mempengaruhi pemberian ASI Ekslusif pada bayi di Puskesmas Talaga Jaya adalah pendidikan ibu, pekerjaan ibu, pelaksanaan IMD, dan dukungan keluarga. Disarankan kepada anggota keluarga untuk dapat ikut berpartisipasi dalam pemberian ASI Eksklusif dengan cara memberikan dukungan selama ibu menyusui sampai 6 bulan.
\end{abstract}

Kata Kunci: ASI Eksklusif, IMD, regresi logistik.

Copyright (C) 2020, Madu Jurnal Kesehatan, Under the license CC BY-SA 4.0

ISSN: 2301-5683 (Print) 
Available Online at http://journal.umgo.ac.id/index.php/madu

\section{PENDAHULUAN}

Air Susu Ibu adalah cairan hasil sekresi kelenjar payudara ibu, sebagai makanan utama yang memiliki kandungan gizi tinggi untuk bayi yang diberikan oleh ibu selama 6 bulan setelah kelahiran secara eksklusif (tanpa tambahan makanan lainnya) dan dilanjutkan selama 2 tahun dengan makanan tambahan (1).

World Health Organization (WHO) dan United Nation Childerns Fund (UNICEF) merekomendasikan hal serupa, dimana bayi sebaiknya hanya disusui dengan air susu ibu hingga berumur 6 bulan, dan pemberian ASI dilanjutkan sampai bayi berumur dua tahun. Sedangkan pemberian ASI selama 6 bulan tanpa memberikan makanan atau minuman pendamping disebut ASI Eksklusif. Berdasarkan penelitian, ASI Eksklusif sangat signifikan bagi kelangsungan hidup bayi (2). ASI memainkan peran penting dalam tumbuh kembang anak, termasuk mencegah kejadian stunting pada anak (3).

Pemerintah Indonesia mengeluarkan berbagai kebijakan terkait ASI Ekslusif, diantaranya regulasi tentang pemberian ASI Eksklusif pada pasal 128 UU No. 36 Tahun 2009 tentang kesehatan dan Peraturan Pemerintah No. 33 Tahun 2012 tentang pemberian ASI Eksklusif. Namun, pemberian ASI Eksklusif di Indonesia semakin menurun seiring meningkatnya umur bayi. Berdasarkan data Profil Kesehatan Indonesia 2019 secara nasional, cakupan bayi yang mendapatkan ASI Eksklusif di Indonesia pada tahun 2019 yaitu sebesar $68,74 \%$. Angka ini telah mencapai target Rencana Strategi tahun 2019 yaitu 50\%. Akan tetapi, beberapa provinsi masih belum mencapai target, salah satunya Provinsi Gorontalo yang hanya mencapai $43,35 \%$ dan berada di urutan ketiga terendah (4). Bahkan di Kabupaten Gorontalo pada tahun 2020, berdasarkan data Dinas Kesehatan Provinsi Gorontalo, mengalami penurunan dan berada diurutan pertama terendah yaitu sebesar
$11,30 \%$, sebelumnya tahun 2019 sebesar 45,4\%. Terdapat lima puskesmas terendah untuk capaian ASI Eksklusif pada bayi 0-6 bulan pada tahun 2020, yaitu Puskesmas Limboto Barat (15,54\%), Talaga Biru $(18,30 \%)$, Talaga Jaya (11,95\%), Bilato $(38,9 \%)$ dan Pulubala $(43,8 \%)$.

Rendahnya cakupan pemberian ASI Eksklusif di Indonesia disebabkan oleh dua faktor, yaitu faktor internal dan faktor eksternal. Faktor internal meliputi umur, pendidikan, pekerjaan, paritas, status gizi ibu, pengetahuan ibu, sedangkan faktor eksternal meliputi kurangnya dukungan keluarga, tingkat penghasilan, pemberian IMD (Inisiasi Menyusui Dini), peran petugas kesehatan maupun pemerintah sebagai pembuat kebijakan terhadap pemberian ASI Eksklusif, gencarnya promosi susu formula, serta adanya faktor sosial budaya (5).

Berdasarkan uraian tersebut, tujuan dilakukan penelitian ini adalah untuk mengetahui faktor-faktor yang mempengaruhi pemberian ASI Eksklusif pada bayi di Puskesmas Talaga Jaya. Hal ini dilakukan karena rendahnya capaian ASI Ekslusif pada bayi 0-6 tahun, yaitu sebesar 11,95\% dan jauh dari target yang telah ditetapkan Puskesmas Talaga Jaya, yaitu sebesar $85 \%$.

\section{METODE}

Penelitian ini dilakukan di wilayah kerja Puskesmas Talaga Jaya yang terdiri dari desa Bunggalo, Bulota, Luwoo, Hutadaa dan Buhu selama 08 April 2021 hingga 15 Mei 2021. Penelitian ini merupakan penelitian Kuantitatif dengan menggunakan jenis penelitian Observasi Analitik dan rancangan penelitian Cross Sectional. Populasi dalam penelitian ini adalah seluruh bayi yang berumur 7-11 bulan di Wilayah Kerja Puskesmas Talaga Jaya Tahun 2020 yang berjumlah 290 orang. Teknik sampling yang digunakan adalah Accindental Sampling, 
Available Online at http://journal.umgo.ac.id/index.php/madu

dengan sampel berjumlah 168 orang. Teknik analisis data yang digunakan adalah Regresi Logistik.

Sebelum memulai $\begin{array}{r}\text { penelitian, } \\ \text { dengan }\end{array}$
dilakukan pra-penelitian
mewawancarai petugas Puskesmas Talaga
Jaya. Dari hasil wawancara diperoleh bahwa
penyebab rendahnya capaian ASI Eksklusif di
Puskesmas ini dikarenakan oleh beberapa
faktor, diantaranya pendidikan ibu, pekerjaan
ibu, pelaksanaan IMD, dukungan keluarga, dan
dukungan petugas kesehatan. Faktor-faktor
inilah yang merupakan variabel independent
dari penelitian ini. Sedangkan untuk variabel
dependent adalah pemberian ASI Ekslusif.

\section{HASIL}

Analisis regresi logistik yang pertama adalah untuk mengetahui pengaruh pendidikan ibu terhadap pemberian ASI Eksklusif di wilayah kerja Puskesmas Talaga Jaya. Hasil disajikan pada tabel 1 .

Berdasarkan tabel 1, diperoleh bahwa dari 49 ibu yang berpendidikan tinggi, terdapat 31 ibu atau sebesar 63,3\% yang tidak memberikan ASI Eksklusif, sedangkan $18 \mathrm{ibu}$ lainnya atau sebesar $36,7 \%$ memberikan ASI
Eksklusif. Sementara itu, dari 119 ibu yang berpendidikan rendah, terdapat $107 \mathrm{ibu}$ atau sebesar $89,9 \%$ yang tidak memberikan ASI Eksklusif, sedangkan 12 ibu lainnya atau sebesar 10,1\% memberikan ASI Eksklusif. Dari hasil juga diperoleh nilai $p$-value $=0,000$, sehingga tolak $\mathrm{H}_{0}$ karena $p$-value $<\alpha(0,05)$. Artinya pendidikan ibu berpengaruh terhadap pemberian ASI Eksklusif.

Analisis regresi logistik yang kedua adalah untuk mengetahui pengaruh pengaruh pekerjaan ibu terhadap pemberian ASI Eksklusif di wilayah kerja Puskesmas Talaga Jaya. Hasil disajikan pada tabel 2.

Berdasarkan tabel 2, diperoleh bahwa dari $47 \mathrm{ibu}$ yang tidak bekerja, terdapat $24 \mathrm{ibu}$ atau sebesar $51,1 \%$ yang memberikan ASI Eksklusif, sedangkan 23 ibu lainnya atau sebesar $48,9 \%$ tidak memberikan ASI Eksklusif. Sementara itu, dari 121 ibu yang bekerja, terdapat 115 ibu atau sebesar 95,0\% yang tidak memberikan ASI Eksklusif, sedangkan 6 ibu lainnya atau sebesar 5,0\% memberikan ASI Eksklusif. Dari hasil juga diperoleh nilai $p$-value $=0,000$, sehingga tolak $\mathrm{H}_{0}$ karena $p$-value $<\alpha(0,05)$. Artinya pekerjaan ibu berpengaruh terhadap pemberian ASI Eksklusif.

Tabel 1. Pengaruh Pendidikan Ibu terhadap Pemberian ASI Eksklusif

\begin{tabular}{ccccccccc}
\hline & \multicolumn{4}{c}{ Pemberian ASI Ekslusif } & \multicolumn{2}{c}{ Total } & \multirow{2}{*}{ p-value } \\
Pendidikan Ibu & \multicolumn{2}{c}{ Ya } & \multicolumn{2}{c}{ Tidak } & \multicolumn{2}{c}{} & \\
& n & \% & n & \% & n & \% & \\
\hline Tinggi & 18 & 36,7 & 31 & 63,3 & 49 & 100,0 & \\
Rendah & 12 & 10,1 & 107 & 89,9 & 119 & 100,0 & 0,000 \\
\hline Jumlah & 30 & 17,8 & 138 & 82,2 & 168 & 100,0 & \\
\hline
\end{tabular}

Sumber: Data Primer, 2021

Tabel 2. Pengaruh Pekerjaan Ibu terhadap Pemberian ASI Eksklusif

\begin{tabular}{ccccccccc}
\hline & \multicolumn{3}{c}{ Pemberian ASI Ekslusif } & \multicolumn{2}{c}{ Total } & p-value \\
Pekerjaan Ibu & \multicolumn{2}{c}{ Ya } & \multicolumn{2}{c}{ Tidak } & & & \\
& n & $\mathbf{\%}$ & n & \% & n & \% & \\
\hline Tidak Bekerja & 24 & 51,1 & 23 & 48,9 & 47 & 100,0 & \\
Bekerja & 6 & 5,0 & 115 & 95,0 & 121 & 100,0 & 0,000 \\
\hline Jumlah & 30 & 17,8 & 138 & 82,1 & 168 & 100,0 & \\
\hline
\end{tabular}

Sumber: Data Primer, 2021

Copyright $\odot$ 2020, Madu Jurnal Kesehatan, Under the license CC BY-SA 4.0 
Available Online at http://journal.umgo.ac.id/index.php/madu

\section{Analisis regresi logistik yang ketiga adalah untuk mengetahui pengaruh pelaksanaan IMD terhadap pemberian ASI Eksklusif di wilayah kerja Puskesmas Talaga Jaya. Hasil disajikan pada tabel 3.}

Berdasarkan tabel 3, diperoleh bahwa dari 36 ibu melaksanakan IMD, terdapat $29 \mathrm{ibu}$ atau sebesar $80,6 \%$ yang memberikan ASI Eksklusif, sedangkan 7 ibu lainnya atau sebesar $19,4 \%$ tidak memberikan ASI Eksklusif. Sementara itu, dari 132 ibu yang tidak melaksanakan IMD, terdapat $131 \mathrm{ibu}$ atau sebesar 99,2\% yang tidak memberikan ASI Eksklusif, sedangkan $1 \mathrm{ibu}$ atau sebesar $0,8 \%$ memberikan ASI Eksklusif. Dari hasil juga diperoleh nilai $p$-value $=0,000$, sehingga tolak $\mathrm{H}_{0}$ karena $p$-value $<\alpha(0,05)$. Artinya pelaksanaan IMD berpengaruh terhadap pemberian ASI Eksklusif.

Analisis regresi logistik yang keempat adalah untuk mengetahui pengaruh dukungan keluarga terhadap pemberian ASI Eksklusif di wilayah kerja Puskesmas Talaga Jaya. Hasil disajikan pada tabel 4.

Berdasarkan tabel 4, diperoleh bahwa dari 30 ibu yang mendapatkan dukungan dari keluarga, terdapat 29 ibu atau sebesar 96,7\% yang memberikan ASI Eksklusif, sedangkan 1 ibu atau sebesar 3,3\% tidak memberikan ASI Eksklusif. Sementara itu, dari 138 ibu yang kurang mendapatkan dukungan dari keluarga, terdapat $137 \mathrm{ibu}$ atau sebesar 99,3\% yang tidak memberikan ASI Eksklusif, sedangkan 1 ibu atau sebesar 0,7\% memberikan ASI Eksklusif. Dari hasil juga diperoleh nilai $p$-value $=0,000$, sehingga tolak $\mathrm{H}_{0}$ karena $p$-value $<\alpha(0,05)$. Artinya dukungan dari keluarga berpengaruh terhadap pemberian ASI Eksklusif.

Analisis regresi logistik yang terakhir adalah untuk mengetahui pengaruh dukungan petugas kesehatan terhadap pemberian ASI Eksklusif di wilayah kerja Puskesmas Talaga Jaya. Hasil disajikan pada tabel 5.

Berdasarkan tabel 5, diperoleh bahwa dari 137 ibu yang mendapatkan dukungan dari petugas kesehatan, terdapat $107 \mathrm{ibu}$ atau sebesar 78,1\% yang tidak memberikan ASI Eksklusif, sedangkan 30 ibu lainnya atau sebesar 21,9\% memberikan ASI Eksklusif. Sementara itu, dari 31 ibu yang kurang mendapatkan dukungan dari petugas kesehatan, seluruhnya tidak memberikan ASI Eksklusif.

Tabel 3. Pengaruh Pelaksanaan IMD terhadap Pemberian ASI Eksklusif

\begin{tabular}{cccccccc}
\hline \multirow{2}{*}{ Pelaksanaan IMD } & \multicolumn{2}{c}{ Pemberian ASI Ekslusif } & \multicolumn{2}{c}{ Total } & \multirow{2}{*}{ Y-value } \\
& $\mathbf{n}$ & $\mathbf{\%}$ & $\mathbf{n}$ & $\boldsymbol{\%}$ & $\mathbf{n}$ & $\boldsymbol{\%}$ & \\
\hline Melaksanakan IMD & 29 & $80,6 \%$ & 7 & 19,4 & 36 & 100,0 & \\
Tidak Melaksanakan IMD & 1 & $0,8 \%$ & 131 & 99,2 & 132 & 100,0 & 0,000 \\
\hline Jumlah & 30 & $17,9 \%$ & 138 & 82,1 & 168 & 100,0 & \\
\hline
\end{tabular}

Sumber: Data Primer, 2021

Tabel 4. Pengaruh Dukungan Keluarga terhadap Pemberian ASI Eksklusif

\begin{tabular}{ccccccccc}
\hline & \multicolumn{4}{c}{ Pemberian ASI Ekslusif } & \multicolumn{2}{c}{ Total } & \multirow{2}{*}{ p-value } \\
Dukungan Keluarga & \multicolumn{2}{c}{ Ya } & \multicolumn{2}{c}{ Tidak } & & & p-val \\
& $\mathbf{n}$ & $\mathbf{\%}$ & $\mathbf{n}$ & $\mathbf{\%}$ & $\mathbf{n}$ & $\boldsymbol{\%}$ & \\
\hline Mendukung & 29 & 96,7 & 1 & 3,3 & 30 & 100,0 & \\
Kurang Mendukung & 1 & 0,7 & 137 & 99,3 & 138 & 100,0 & 0,000 \\
\hline Jumlah & 30 & 17,9 & 138 & 82,1 & 168 & 100,0 & \\
\hline
\end{tabular}

Sumber: Data Primer, 2021

Copyright $(9) 2020$, Madu Jurnal Kesehatan, Under the license CC BY-SA 4.0 
Available Online at http://journal.umgo.ac.id/index.php/madu

Dari hasil juga diperoleh nilai $p$-value $=0,000$, sehingga gagal tolak $\mathrm{H}_{0}$ karena $p$ value $>\alpha(0,05)$. Artinya dukungan dari petugas kesehatan tidak berpengaruh terhadap pemberian ASI Eksklusif.

\section{PEMBAHASAN}

Dari hasil penelitian diperoleh bahwa faktor "pendidikan ibu" berpengaruh terhadap pemberian ASI Ekslusif, dengan ibu yang memiliki pendidikan tinggi dan memberikan ASI Eksklusif adalah sebesar 36,7\%. Hal ini mengindikasikan bahwa ibu yang berpendidikan tinggi akan lebih baik penerimaannya terhadap ASI Eksklusif dan lebih berupaya untuk mempraktikkannya. Hasil ini sejalan dengan penelitian yang dilakukan oleh Jannah (2015) yang mengatakan bahwa ibu yang memiliki tingkat pendidikan tinggi mempunyai sikap yang tinggi dalam pemberian ASI Eksklusif (6).

Dari hasil penelitian juga diperoleh bahwa ibu yang memiliki pendidikan tinggi namun tidak memberikan ASI Eksklusif adalah sebesar $63,3 \%$. Penyebab dari hasil ini, yaitu faktor "pekerjaan ibu", dimana pekerjaan menjadi alasan ibu untuk tidak memberikan ASI Eksklusif pada bayi. Hal ini tampak pada hasil distribusi pekerjaan ibu, yaitu sebesar $72 \%$ ibu yang memiliki pekerjaan. Pekerjaan inilah yang dapat menghambat ibu dalam memberikan ASI Eksklusif pada bayi, karena harus berada diluar rumah untuk bekerja dan tidak mengetahui cara melakukan dan menyimpan ASI yang benar. Hal ini diperkuat oleh hasil penelitian yang dilakukan oleh Sitorus (2016) yang menyatakan bahwa beban pekerjaan ibu dapat memengaruhi kualitas pola asuh pada anak. Seorang ibu yang memiliki kewajiban untuk bekerja cenderung memiiliki waktu yang sedikit untuk menyusui bayinya akibat kesibukkan kerja, keadaan ini menyebabkan ibu menghentikan pemberian ASI pada bayi (7).

Selain itu, kurangnya dukungan serta bantuan dari keluarga terhadap ibu untuk memberikan ASI pada bayi sampai bayi berusia 6 bulan dapat menjadi penyebab terhentinya pemberian ASI. Dari hasil penelitian diperoleh ibu yang memiliki pendidikan rendah namun tetap memberikan ASI Eksklusif sebesar 10,1\%. Berdasarkan hasil di lapangan, bahwa mereka mendapatkan dukungan dari keluarga dan petugas kesehatan untuk memberikan ASI sampai bayi berusia 6 bulan sehingga permasalahan menyusui dapat diatasi dengan mudah.

Dari hasil penelitian diperoleh bahwa faktor "pekerjaan ibu" berpengaruh terhadap pemberian ASI Ekslusif, dengan ibu yang tidak bekerja dan memberikan ASI Eksklusif adalah sebesar $51,1 \%$. Hal ini mengindikasikan bahwa ibu yang tidak bekerja mempunyai waktu yang cukup untuk selalu mendampingi bayinya, sehingga pemberian ASI kepada bayinya dapat diberikan sewaktu-waktu. Hasil ini sejalan dengan penelitian yang dilakukan oleh Sitorus (2016) bahwa ibu yang tidak bekerja berpeluang 2 kali lebih banyak dalam memberikan ASI Eksklusif dibandingkan ibu

Tabel 5. Pengaruh Dukungan Petugas Kesehatan terhadap Pemberian ASI Eksklusif

\begin{tabular}{ccccccccc}
\hline \multirow{2}{*}{$\begin{array}{c}\text { Dukungan Petugas } \\
\text { Kesehatan }\end{array}$} & \multicolumn{2}{c}{ Yemberian ASI Ekslusif } & \multicolumn{2}{c}{ Total } & \multirow{2}{*}{ Yavalue } \\
& $\mathbf{n}$ & $\boldsymbol{\%}$ & $\mathbf{n}$ & $\mathbf{\%}$ & $\mathbf{n}$ & $\mathbf{\%}$ & \\
\hline Mendukung & 30 & 21,9 & 107 & 78,1 & 137 & 100,0 & \\
Kurang Mendukung & 0 & 0 & 31 & 100,0 & 31 & 100,0 & 0,998 \\
\hline Jumlah & 30 & 17,1 & 138 & 82,1 & 168 & 100,0 & \\
\hline
\end{tabular}

Sumber: Data Primer, 2021

Copyright $\odot$ 2020, Madu Jurnal Kesehatan, Under the license CC BY-SA 4.0

ISSN: 2301-5683 (Print) 
Available Online at http://journal.umgo.ac.id/index.php/madu

yang bekerja (7). Dari hasil penelitian juga diperoleh bahwa ibu yang tidak bekerja namun tidak memberikan ASI Eksklusif, yaitu sebesar 48,9\%. Berdasarkan hasil di lapangan, bahwa ibu yang tidak bekerja beralasan banyaknya pekerjaan rumah yang menguras waktu dan tenaga menyebabkan ibu tidak dapat memberikan ASI Eksklusif, sehingga bayi diberikan susu formula sebelum berusia 6 bulan. Selain itu, pada penelitian ini juga diketahui bahwa mereka kurang mendapatkan dukungan dari keluarga untuk memberikan ASI Eksklusif.

Dari hasil penelitian juga diperoleh bahwa ibu yang bekerja namun tetap memberikan ASI Eksklusif, yaitu sebesar 5\%. Berdasarkan hasil di lapangan, mereka ini mendapatkan dukungan baik dari keluarga maupun petugas kesehatan. Salah satu upaya yang dilakukan untuk tetap menyusui adalah mereka memerah ASI Eksklusif sebelum pergi bekerja. Hal ini dilakukan setelah mengetahui informasi terkait hal tersebut dari tenaga kesehatan maupun media, baik media cetak maupun media visual tentang pentingnya manfaat dan kandungan dari ASI serta cara melakukannya dan menyimpan ASI.

Dari hasil penelitian diperoleh bahwa faktor "pelaksanaan IMD" berpengaruh terhadap pemberian ASI Ekslusif, dengan ibu yang melaksanakan IMD dan memberikan ASI Eksklusif adalah sebesar 80,6\%.24 jam setelah ibu melahirkan adalah saat yang sangat penting untuk keberhasilan menyusui selanjutnya. Hal ini mengindikasikan bahwa Ibu yang melakukan IMD cenderung memberikan ASI Eksklusif pada bayinya dibandingkan ibu yang setelah proses persalinan tidak melaksanakan IMD. Hasil ini sejalan dengan penelitian yang dilakukan oleh Rizqi (2019) yang menyatakan bahwa Inisiasi menyusui dini pada bayi turut peran dalam keberlanjutan pemberian ASI sampai 6 bulan pada bayi (8).
Dari hasil penelitian juga diperoleh bahwa ibu yang melaksanakan IMD namun tidak memberikan ASI Eksklusif, yaitu sebesar 19,4\%. Berdasarkan hasil di lapangan, mereka mengaku mengalami masalah saat masa menyusui diantaranya air susu yang keluar sedikit sedangkan bayinya terus menangis sehingga membuat ibu mengambil keputusan untuk memberikan susu formula. Hal inilah yang menyebabkan produksi ASI semakin hari semakin menurun, karena semakin sering bayi menyusui maka produksi ASI akan semakin lancar.

Dari hasil tabulasi silang antara faktor "pekerjaan ibu" dan "pelaksanaan IMD sebesar $30,6 \%$ ibu yang memiliki pekerjaan. Walaupun ibu melaksanakan IMD namun tuntutan pekerjaan yang mengharuskan ibu meninggalkan bayi, membuat ibu memilih memberikan susu formula kepada bayi.

Dari hasil tabulasi silang antara faktor "pelaksanaan IMD" dengan "pendidikan ibu", diperoleh ibu yang tidak melaksanakan IMD majoritasnya berpendidikan rendah. Hal ini dapat diartikan bahwa kurangnya pengetahuan responden tentang pentingnya dan manfaat pemberian IMD, dimana pelaksanaan IMD ini masih dianggap baru, sehingga menimbulkan keraguan dan kesulitan untuk menerapkannya serta masih melekatnya pengetahuan budaya lokal tentang pemberian makan pada bayi. Hasil ini sejalan dengan penelitian yang dilakukan oleh Karnita (2018) yang menyatakan bahwa Pendidikan ibu berpengaruh terhadap ASI Eksklusif dan IMD. Ibu yang memiliki pendidikan tinggi akan lebih penerimaannya terhadap ASI Eksklusif dan IMD serta lebih berupaya untuk mempraktikannya (9).

Dari hasil penelitian juga diperoleh ibu yang tidak melaksanakan IMD namun tetap memberikan ASI Eksklusif, yaitu sebesar $0,8 \%$. Berdasarkan hasil di lapangan, mereka 
Available Online at http://journal.umgo.ac.id/index.php/madu

mengatakan bahwa proses persalinan mengalami kelelahan sehingga dokter ataupun bidan tidak melaksanakan IMD. Akan tetapi ASInya lancar sehingga dapat memberikan ASI Eksklusif pada bayinya.

Dari hasil penelitian diperoleh bahwa faktor "dukungan keluarga" berpengaruh terhadap pemberian ASI Ekslusif, dengan ibu yang memperoleh dukungan keluarga dan memberikan ASI Eksklusif adalah sebesar 96,7\%. Dukungan dari lingkungan keluarga termasuk suami, orang tua maupun saudara lainnya sangat mempengaruhi keberhasilan dalam proses menyusui, karena berpengaruh terhadap kondisi ibu sehingga secara tidak langsung mempengaruhi produksi air susu ibu. Seorang ibu yang mendapatkan dukungan dari suami dan anggota keluarga lainnya cenderung memberikan ASI Eksklusif (10).

Dari hasil penelitian juga diperoleh ibu yang memperoleh dukungan keluarga, namun tidak memberikan ASI Eksklusif, yaitu sebesar $3,3 \%$. Berdasarkan hasil di lapangan, alasan ibu tidak memberikan ASI Eksklusif adalah karena proses melahirkan ibu tersebut adalah dengan cara operasi caeser. Hal ini mengakibatkan ibu masih dalam pengaruh obat bius, sehingga tidak dapat menyusui bayinya dan langsung diberikan susu formula tanpa melakukan IMD. Selain itu, ibu tersebut mengaku mengalami permasalahan dalam memberikan ASI yakni air susu yang keluar hanya sedikit, maka pemberian ASI dikombinasikan dengan pemberian susu formula.

Dari hasil penelitian juga diperoleh mayoritas ibu kurang mendapatkan dukungan keluarga, kemudian tidak memberikan ASI Eksklusif, yaitu sebesar 99,3\%. Hal ini mengindikasikan kurangnya perhatian dan komunikasi keluarga dengan ibu menyusui dan juga kesibukan masing-masing anggota keluarga. Berdasarkan hasil di lapangan, mereka mengatakan hal ini disebabkan oleh beberapa keadaan, diantaranya karena keluarga jarang menemani ibu menyusui pada waktu luang, tidak ada keluarga yang membimbing ibu tentang cara memerah ASI, kurangnya pujian kepada ibu karena sudah menyusui bayinya serta kurang informasi dari keluarga tentang manfaat dan pentingnya memberikan ASI Eksklusif.

Dari hasil penelitian juga diperoleh ibu yang kurang memperoleh dukungan keluarga namun tetap memberikan ASI Eksklusif, yaitu sebesar 0,7\%. Berdasarkan hasil dilapangan ibu tersebut tetap memberikan ASI Eksklusif karena ASI-nya lancar dan kemauan dari ibu sendiri ingin memberikan ASI Eksklusif pada bayinya, dimana ibu merasa manfaat ASI lebih baik dari pada susu formula. Selain itu, diketahui bahwa ibu ini memperoleh dukungan dari petugas kesehatan yang meyakinkannya untuk dapat memberikan ASI sampai bayi berusia 6 bulan.

Dari hasil penelitian diperoleh bahwa faktor "dukungan petugas kesehatan" tidak berpengaruh terhadap pemberian ASI Ekslusif.

\section{KESIMPULAN DAN SARAN}

Dari hasil penelitian dapat
disimpulkan bahwa faktor-faktor yang mempengaruhi pemberian ASI EKslusif pada bayi di Puskesmas Talaga Jaya adalah pendidikan ibu, pekerjaan ibu, pelaksanaan IMD, dan dukungan keluarga. Disarankan kepada anggota keluarga untuk dapat ikut berpartisipasi dalam pemberian ASI Eksklusif dengan cara memberikan dukungan selama ibu menyusui sampai 6 bulan.

\section{DAFTAR PUSTAKA}

1. Mubarokah AZ. Pengaruh Faktor Psikologi Dan Sosio Budaya Gizi Terhadap Pemberian Asi Eksklusif Pada Bayi Di Puskesmas Bangkalan, Kabupaten Bangkalan, Madura. Universitas Airlangga; 2019. 
2. Wendiranti Ci, Subagio Hw, Wijayanti Hs. Faktor Risiko Kegagalan Asi Eksklusif. Diponegoro University; 2017.

3. Nurdin SSI, Katili DNO. Faktor Risiko Balita Pendek (Stunting) Di Kabupaten Gorontalo. J Antara Kebidanan. 2019;2(4):50-60.

4. Kemenkes. Riset Kesehatan Dasar Tahun 2018. Jakarta: Kementrian Kesehatan Republik Indonesia; 2018.

5. Prasetyono DS. Buku Pintar Asi Eksklusif. Yogyakarta: Diva Press; 2012.

6. Jannah AM. Faktor-Faktor Yang Berhubungan Dengan Perilaku Pemberian Asi Eksklusif Pada Bayi Usia 6-12 Bulan Di Kelurahan Gerem Wilayah Kerja Puskesmas Grogol Kota Cilegon Tahun 2015. Uin Syarif Hidayatullah Jakarta: Fakultas Kedokteran Dan Ilmu Kesehatan, 2016; 2016.

7. Sitorus SBM. Pengaruh Dukungan Keluarga Dan Faktor Sosial Budaya Terhadap Pemberian Asi Eksklusif Pada Bayi 0-6 Bulan Di Wilayah Kerja Puskesmas Sukaraya Kecamatan Pancurbatu Kabupaten Deli Serdang. 2016;

8. Fadlliyyah UR. Determinan Faktor Yang Berpengaruh Pada Pemberian Asi Eksklusif Di Indonesia. Ikesma. 2019;15(1):37-42.

9. Karnita. Hubungan Karakteristik Dan Tingkat Pengetahuan Ibu Dengan Pemberian Asi Eksklusif Di Wilayah Kerja Puskesmas Koba Tahun 2017. Politeknik Kesehatan Kementerian Kesehatan. Yogyakarta. 2018.

10. Nabilla. Hubungan Antara Persepsi Dengan Perilaku Ibu Menyusui Menurut Teori Health Belief Model Di Desa Singojuruh Kecamatan Singojuruh Kabupaten Banyuwangi. Fakultas Kedokteran. Universitas Airlangga; 2016. 